\title{
Women and Their Clitoris: Personal Discovery, Signification, and Use
}

\author{
Dennis D. Waskul \\ Minnesota State University, Mankato \\ Phillip Vannini \\ Royal Roads University \\ Desiree Wiesen \\ Minnesota State University, Mankato
}

\begin{abstract}
Under continued, broad, and pervasive conditions of symbolic clitoridectomy - a bracketing of the clitoris by means of linguistic and discursive erasure-the carnal discovery of the clitoris poses circumstances where women often confront and negotiate symbolic purgatory, a situation in which most women discover "it" long before they fully acquire the symbolic knowledge that it, indeed, is a clitoris. Based on the written reports of fifteen women, we provide idiographic descriptions of women's reported recollections of the clitoris by investigating three related dynamics: (1) how women interpret the meanings of the clitoris in circumstances relatively absent of significant symbols; (2) how the clitoris becomes a significant symbol for women; and (3) how broader discourses inform how women make meaning of the clitoris. This study documents a clitoral somatic career that is marked by three important junctures of discovery, knowledge, and meaning making: discovering the sensations of the clitoris, putting the clitoris into discourse, and negotiating contested uses of pleasure. As we argue, the sensual embodiment of the clitoris is emergent in active and reflective practices in which women both sense and make sense.
\end{abstract}

Removing the clitoris most certainly affects a woman's sexual pleasure; however, societal silence regarding the role of the clitoris may act similarly as a symbolic clitoridectomy.

- Shirley M. Ogletree and Harvey J. Ginsburg, "Kept under the Hood: Neglect of the Clitoris in Common Vernacular" (2000)

Direct all correspondence to Dennis Waskul, 113 Armstrong Hall, Minnesota State University, Mankato, MN 56001; e-mail: dennis.waskul@mnsu.edu.

Symbolic Interaction, Vol. 30, Issue 2, pp. 151-174, ISSN 0195-6086, electronic ISSN 1533-8665. (C) 2007 by the Society for the Study of Symbolic Interaction. All rights reserved. Please direct all requests for permission to photocopy or reproduce article content through the University of California Press's Rights and Permissions website, at http://www.ucpressjournals.com/reprintinfo.asp. DOI: 10.1525/si.2007.30.2.151. 


\section{I don't really think about my clitoris that much, or at least not that I'm aware of. If I do think about it I almost think that I shouldn't. \\ -Kari}

By "symbolic clitoridectomy" Ogletree and Ginsburg (2000; see also Bennett 1993 on "critical" clitoridectomy) refer to silence, taboo, and failure to identify or define-a bracketing of the clitoris by means of linguistic and discursive erasure. ${ }^{1}$ As the present article illustrates, symbolic clitoridectomy also poses circumstances where women often confront and negotiate symbolic purgatory, a situation in which most women discover "it" long before they fully acquire the symbolic knowledge that it, indeed, is a clitoris. We intend symbolic purgatory as a sensitizing (and provoking) concept (Blumer 1954) referring to experiences relatively devoid of symbolic meaning and rife with opportunities for semiotic "awakening" (Leder 1990). Such is the case for the women in this study, all of whom reported a significant gap between the carnal discovery of their clitoris and full acquisition of the symbolic knowledge that the clitoris is a standard part of female genitalia. This purgatory begs provocative questions about meaning, language, somatic experience, and, in this case, their interstices in what is generally deemed the most private realm of the corporeal body.

As an object the clitoris is an anatomical organ-but as a subject it is contested social terrain: an epicenter of female sexuality in which pleasure and repression collide on an embodied fault line that is both private and public, political and existential, symbolic and corporeal. As an organ the clitoris is a source of potentially pleasing sensuality. As an icon, the clitoris is polysemous: its signification is negotiated in a multiplicity of subjective sensations, experiences, and reflexive acts of sense making. Thus, if "embodiment is the lived experience of the sensual or subjective body" (Turner 2000:492, emphasis added), then the unvarnished sensuality of the clitoris, in the context of its contested subjectivity, presents precarious dynamics of embodimentas well as evocative opportunities for explorations of a truly "carnal" sociology (Crossley 1995a, 1995b).

Interactionist understandings of mind, self, and society generally hinge on linguistic reflexivity: people interact with themselves as much as with others-and primarily through significant symbols. The same applies to the body and reasonably characterizes interactionist contributions to the sociology of the body (see Strauss 1993; Waskul and Vannini 2006): by use of symbols people perceive, interact, and interpret their own body as much as they sense, interact with, and interpret the bodies of others. However, linguistic or symbolic reflexivity has limits (DeNora 1997; RochbergHalton 1982). Because the body is our "first property" (Simmel 1950:322n, 344), its presymbolic "qualitative immediacy" (Dewey 1929, [1934] 1958) or firstness (Peirce 1958) assures a ubiquitous source of sensation and meaning. In other words, somatic experience is reflexive and meaningful even in the absence of significant symbols.

How, exactly, do we experience the qualitative immediacy of corporeal sensation in the relative absence of symbolic meaning? Or, specific to this study, what happens 
when we experience a part of our body in circumstances in which symbols for identification and meaning making are relatively absent? We answer this central question by investigating three related dynamics: (1) how women interpret the meanings of the clitoris in circumstances relatively absent of significant symbols; (2) how the clitoris becomes a significant symbol for women; and (3) how broader discourses inform how women make meaning of the clitoris. Our goal is twofold: on the one hand, we concern ourselves with idiographic description of women's reported bodily experiences and hermeneutic practices; on the other, we aim at building sociological knowledge on sensation and carnality.

\section{SYMBOLIC CLITORIDECTOMY AND SYMBOLIC PURGATORY}

Except for the obvious, derisive "clit," I find no common slang wordsno common words at all-for the clitoris, the great unmentionable, the only human organ with the single purpose of pleasure. This is an oversight almost impossible to believe, and it makes me wonder at the depth of our capacity to suppress our experience-to suppress it so deeply, even the making of language is stopped. - Sally Tisdale, Talk Dirty to Me: An Intimate Philosophy of Sex (1994)

I don't remember ever being told that a clitoris is a normal part of a female's body. - Rebecca

Women's genitalia are generally unspeakable (Allan and Burridge 1991) and a site of considerable taboo (Braun 1999). In fact, "many people appear to consider women's genitalia to be unmentionable" (Braun and Kitzinger 2001a:146), and "language is rarely used to refer to the vagina (or women's genitalia more generally) in any detail" (Braun and Wilkinson 2001:19). The vulva is imprecisely defined, and its parts are often conspicuously absent in formal medical and dictionary definitions as well as in informal slang (Braun and Kitzinger 2001a). In place of terms that differentiate the various anatomical parts of the vulva, the word vagina is colloquially and popularly used to refer to the entire area "down there." Accordingly, "a language that does not enable women to talk about the different parts of the genitalia, or to conceptualize the genitalia as comprised of various parts, might perpetuate the absence of women's genitalia from their conceptualized body" (Braun and Kitzinger 2001a:155).

Vulva taboos are reflected and reinforced in a relative scarcity of language, and the clitoris may be the most muted of all. In Western culture the clitoris remains a part of women's bodies that eschews naming and mention (Bennett 1993; Ogletree and Ginsburg 2000). Throughout history the clitoris has irregularly cycled through hiding, discovery, degradation, reinvention, and destruction (Moore and Clarke 1995; Scheper-Hughes 1991). Even the history of the scientific study of anatomy 
shows wide-ranging variations in the technical construction of the clitoris, which have often classified the clitoris as homologous or analogous to the penis (Moore and Clarke 1995). The result is a symbolic clitoridectomy in which "it" is "kept under the hood" (Ogletree and Ginsburg 2000:917, 925) in a subdued state of symbolic purgatory-one of the many outcomes of discursive practices that have historically contributed to the hystericization of women's bodies (Foucault 1979). The conditions and consequences of symbolic clitoridectomy have provoked substantial critique: the hush reflects and perpetuates "the blank balance sheet of our society's concern for women's pleasure" (McClintock 1992:115); contributes to both silencing and control of women's sexuality (see Cornog 1986; Gartrell and Mosbacher 1984; Lerner 1976); reinforces vaginal rather than clitoral constructions of feminine sexual pleasure (see Bennett 1993); and contributes to a partial absence of genitalia from women's conceptualized bodies (see Braun and Kitzinger 2001a, 2001b; Braun and Wilkinson 2001; Moore and Clarke 1995; Ogletree and Ginsburg 2000).

It might seem that symbolic clitoridectomy is an obvious case of repression, a "repression that operate[s] as a sentence to disappear" (Foucault 1984:293). However, symbolic clitoridectomy is consistent with Foucauldian arguments on biopower and technologies of the body (see Foucault 1979, 1980). Symbolic clitoridectomy operates as a specific political anatomy strategy, a technology of the body that incites awareness, self-knowledge, and speaking the truth by way of erasing the clitoris; a mechanism by which "it" and its experiences are placed in a purgatorywhere ignorance and partial knowledge ironically coexist-and abundant discourses "make possible [its] discovery" (Foucault 1979:43). There is a relative scarcity, but not absolute lack, of discursive resources to negotiate the meanings of women's bodies and sexualities. In fact, a Janus-faced condition exists: a dearth of symbolic meaning in the context of multiple discourses for potential discovery. ${ }^{2}$ Thus, borrowing from a classic Heideggerian and Derridean technique, we characterize symbolic clitoridectomy as putting the clitoris "under erasure," allowing it to be implicitly present in discourse under conditions of its explicit absence-as we illustrate below.

\section{METHOD AND DATA}

This study was conducted at Minnesota State University, Mankato. Because data collection procedures required women to reveal personal and potentially embarrassing information, we relied on a purposive sample and an elaborate procedure to assure anonymity. Women qualified for this study if they were enrolled in or successfully completed a sexualities course taught by Dennis Waskul. We felt this population of women would be more likely to participate because of their exposure to a multiplicity of discourses on sexuality. We acknowledge the limitations of this sampling procedure - the sample is not representative, and the data likely reflect volunteer bias; we suspect that women with some of the most evocative and perhaps troubling experiences were the least likely to volunteer for this study. 
By e-mail we initially contacted sixty-four women and individually invited them to participate in a research project on women's private and personal sexual experiences of their bodies. We further asked each woman to reply by e-mail if interested in participating. Forty-one women responded. Respondents subsequently received another e-mail that disclosed the research procedures, methods to guarantee relative anonymity, and all research questions. We informed women that, should they choose to participate in this study, we would provide them with a notebook and a list of questions that they would answer privately and with complete anonymity (on this and similar methods see Plummer 2001). Questions elicited basic demographic data as well as the women's earliest recollections of discovering their clitoris, earliest recollection of having been told or otherwise learned about the clitoris as a normal part of female anatomy, history with masturbation, and so on.

Women willing to participate in this study were responsible for sending an e-mail to Desiree Wiesen, who would arrange a time and place to have them sign a research consent form and would provide them with the research materials. We informed the respondents that Wiesen would collect and seal all research consent forms (in the unlikely event that they would ever be needed); she also collected and securely sealed all notebooks, which were immediately provided to Waskul. We further informed women that neither Waskul nor Phillip Vannini would have access to the research consent forms and Wiesen would not have access to the contents of their notebooks. These procedures - the strategic use of e-mail and our division of methodological and analytic labor-were designed to assure double-blind anonymity; we do not know who agreed to participate in this study and only by unsealing the research consent forms (in the possession of Wiesen) is it possible to identify those participants or match any one woman with the data she provided.

Twenty women signed consent forms and received research materials, and fifteen women returned completed notebooks. While we initially hoped for a larger sample, we also understood women's hesitation in revealing such personal information. However, in the end, a sample of fifteen proved satisfactory. The research procedures provided a private and anonymous discursive space in which women wrote exceedingly rich accounts. Women answered thirteen questions and collectively provided a total of 204 handwritten pages of text.

Our sample is overwhelmingly Caucasian; only one woman identified herself as nonwhite. The sample is equally homogeneous in other categories. Ages narrowly ranged from nineteen to twenty-two. Nine women described their upbringing as "rural"; five as a mix of "rural" and "urban" environments; one woman described her upbringing as "urban." Ten women identified themselves as either "heterosexual" or "straight"; one woman identified herself as "mostly heterosexual"; one described her sexual orientation as "straight, although I've kissed girls when I've/ we've been drinking a lot"; one woman wrote "my orientation changes depending on the situation I'm in"; one woman identified herself as "bisexual"; and one woman did not identify a sexual orientation. Five women described themselves as "single"; four claimed to be "engaged"; one woman wrote that she is "soon to be engaged I hope"; 
the remaining five women described themselves as in "long term," "serious," or "cohabitating" relationships with men. One woman in this study described herself as a "virgin." We refer to all women in this study by pseudonyms.

Our analysis of the data follows the procedure of phenomenological research methods (Moustakas 1994:118-19). Organization and analysis of data entail a process of (1) horizonalizing the data-that is, "regarding every horizon or statement relevant to the topic and question as having equal value" (p. 118); (2) clustering units of meaning from the horizonalized data into common themes, thus removing overlaps and repetitions; (3) developing descriptions of experiences, based on clusters of meaning units; and (4) integrating textual descriptions into the meaningsexperiential and theoretical—of the phenomena under investigation.

\section{CLITORAL ERASURE AND A SOCIALIZATION OF GENITAL IGNORANCE}

Young women's understandings of their bodies are shaped and constrained by the processes of social construction of gender which provide limited ways in which they can recognize and legitimate their bodily experiences and practices. - Janet Holland, Caroline Ramazanoglu, Sue Scott, and Rachel Thompson, "Desire, Risk, and Control: The Body as a Site of Contestation" (1994)

Here I am a twenty-year-old woman and I still do not know much about my genitals. - Rebecca

Derived from the Greek kleitoris, meaning "hill" or "slope," even etymology cloaks the delectable clitoris. No mere "hill" or "slope"-semantically significant only for its shape or form - the clitoris is the most sensitive female sex organ; pleasure is its only known function. Certainly, "female sexuality, like female pleasure, is multiply sited. It presents, therefore, multiple ways in which it can be constructed - as well as experienced-by individual women" (Bennett 1993:238). Nonetheless, as all the women in this study testify, the clitoris is a corporeal epicenter of embodied female sexuality:

Without my clitoris, I believe I'd still be an orgasm virgin. . . . clit stimulation is the only way I can be sexually orgasmic. . . . The clitoris is the most important part of sexual satisfaction and gratification, whether I'm solo or partnered up. (Cindy; emphasis in original)

All the other stuff is fun, but doesn't really matter unless my clit gets attention.... I get some pleasure from the other things but it always goes back to my clit $100 \%$. (Danielle)

The women in this study bestowed enormous significance on and fondness for their clitoris. As Jessica claimed, "Seriously, the clitoris was God's gift to women! (I almost pity men for all the opportunities unavailable to them)." Both Rochelle and Diana audaciously announced, "I love my clitoris!" These sentiments are understandable, 
but beg a question: in light of its affectionate, pleasurable, and orgasmic significance, how do women learn about the clitoris?

Women reported various circumstances in which they discovered and learned about their clitoris. However, one striking commonality is the frequent claim that they did not acquire this information in primary and secondary educational settings. As Jill recalled, "I don't remember ever being told about the clitoris. . . . we never covered genitalia in the health classes at school. I don't remember covering human anatomy at all." Similarly, Rochelle claimed:

[The] "Family Life" program in school (fifth grade) showed me the pictures, but did not detail the parts. Probably my freshman year of high school is actually when we heard the parts explained in health class. (emphasis in original)

Several women equally testified to this curricular omission that, as they recalled, was especially impoverished regarding the functions of various parts of their genitalia. This was certainly Vicki's experience: "Our teacher just explained what each part of the body and girls' anatomy was. But didn't really tell us anything about what each thing was for." Of course, adequate instruction on the clitoris would necessarily identify its function-purely pleasure. But because pleasure, especially children's pleasure, is not organized in terms of generation and reproduction, it did not "merit a hearing" (Foucault 1984:293). As several women recalled, the clitoris was "driven out, denied, and reduced to silence" (p. 293):

In seventh grade health class we went over the anatomy of the human body. I remember learning about the vagina and the many parts of it, but never was clitoris mentioned. (Ann; emphasis added)

When I went through sex ed. in fifth grade we didn’t even really learn what sex really was. We just learned about the parts of our anatomy-excluding the clitoris — and about periods and hygiene. (Sara; emphasis added)

Children are assumed to have "no sex, which is why they were forbidden to talk about it," and this perhaps also explains why, in place of a curriculum that includes the clitoris, "a general and studied silence was imposed" (p. 293). Consequently, many women recalled entering and experiencing puberty and adolescence relatively uneducated about a significant component of their changing body, genitals, and sexuality. Indeed, despite the fact that nearly all the women in this study had been sexually active for quite some time, they commonly reported learning about the clitoris in their late teenage years - often as a college or university studentwhen discourses on sex have assumed the mantra of scientific propriety:

When I found out the name, the clitoris, I was seventeen yrs old. It happened in my biology class in college. . . I don't remember discussing the sexual function of the clitoris. Mainly I found out this part of my genitals had a name. It wasn't until other college classes that I began to fully understand the concept of a clitoris.... Besides professors talking about it, the clitoris was included in some textbooks, supplemental reading, and magazines. All of this information made me realize that the clitoris is for pleasure and is biologically highly sensitive because of nerve endings. (Jennifer) 
Women generally reported equal silence from parents. Vicki wrote, "I was actually never told anything about it from my parents." For Jill, "it was never something that was talked about in my house, not even between my mom and I." Although some parents were more willing to talk about sex, this did not necessarily mean they told their daughters about the parts that comprise their genitalia. Sara recalled: "My parents were very open with me about sex, but they never focused on the actual parts of the vagina." Parents were not alone in their discomfort with the subject; in some cases, young girls were themselves part of a coalition of evasion and avoidance. As Rebecca explained, "I wasn't comfortable talking to my parents about it, and they weren't comfortable talking to me about it."

Foucault argued that silence and repression can only partially explain the rapport between sex, knowledge, and power. Similarly, symbolic clitoridectomy is marked as much by silence as by see-through-secrecy. In fact, discourses on sexuality and the clitoris are rather straightforwardly available in certain public arenas where sex can be safely administered (like university classrooms) or educational resources. Owing to this see-through-secrecy of a society that speaks "verbosely of its own silence" (Foucault 1984:297), some parents relied on these other means of informing girls about their body and sexuality. Books, in particular, proved useful for Rebecca and her parents-a common recollection for the women in this study:

I remember when my sister and I were young, probably around the age of 9 or 10 , our mother checked out a library book that taught young children about sex. When she showed us we were embarrassed and to make it worse, our father was there, which made us more uncomfortable. We didn't want to look at the book or talk about it. She put it under the couch and said that if we wanted to look at it we could. So, later that day I snuck it out from under the couch and took it into the bathroom and quickly looked at it. (Rebecca)

Although books may have proven helpful, they too provided a means of maintaining a vow of see-through-secrecy for parents and children alike. Books were relatively available, but girls were on their own to read them. Neither parents nor children seemingly needed to discuss the matter further. Still, the availability of books, in this case, enabled these women to learn about conceptualizations of the clitoris (although on the limitations of these books, see Moore and Clarke 1995) and thus, as we show, provided them the chance to "exit" symbolic purgatory.

While parents were not always forthcoming, many women found adequate comfort in asking them questions or in feeling they could talk to them-mothers, in particularif they had questions (even if they never recalled doing so). As Cheryl explained, "I always knew that if I wanted to know I could probably ask my mom, who was a nurse. . . . I knew I could go to my parents with specific questions." And parents were sometimes quite helpful in assuring daughters who were sometimes confused about their changing bodies:

When I was young, I was very inquisitive about my body. I asked numerous questions and they were answered to the best of my parents abilities and comfort levels. I remember discovering my pubic hair one night while I lay in bed. 
I quickly rushed downstairs to ask my mother what it was and why it was there. She comforted me by saying it was natural and that eventually all girls have hair there. (Rebecca)

More than a quaint story, Rebecca's mother was an important source of comforting knowledge during a time of change and apprehension. Indeed, "put[ting] sex into discourse" (Foucault 1984:299) can be important for girls who, in the absence of other information, may worry unnecessarily about their bodies and sexual subjectivity. Vicki recalled an especially evocative memory:

I was very young, about four maybe, and I noticed it [clitoris] when I was getting dressed or something. I just remember thinking I was weird because I had bathed with my girl cousins and never remembered seeing theirs, and no one had ever told me anything about it. I got really confused about it, and eventually upset enough that I asked my mom about it. I was afraid that I must be part boy, and this was like a mini-penis or something. I remember being very concerned about what I was, if I was a boy/girl. My mom kind of giggled at me and told me I was $100 \%$ girl, and it was just a part of my vagina. And all girls had it.

Significantly, Vicki was "very concerned about what [she] was" because, even as a young girl, she was aware that boys have a penis; she was not aware that girls have a clitoris. Her anxiety stemmed from the fact that girls "are rarely taught the anatomical terms which differentiate parts of female genitalia (e.g., the clitoris, the inner and outer labia) - the word vagina covers the whole area" (Braun and Kitzinger 2001a:155; also see Gartrell and Mosbacher 1984; Lerner 1976). The symbolic purgatory of the clitoris compelled Vicki to seek available discourses, appropriate known icons-a penis-and worry that what she discovered "was like a mini-penis." Her clitoris was a part of her corporeal body, but not part of the body she conceptualized through language. By putting sex into discourse, her mother offered reassurances that restored order to Vicki's purgatory and eased her anxiety about being "a boy/girl."

Taking into account a genital disembodiment or alienation of children from their own bodies, as well as the relative silence, avoidance, and omissions of family and school, it is not surprising that women generally recalled growing up ignorant about their genitals. Indeed, almost none of our informants learned that their genitals were composed of various parts until well into their teenage years:

I think I was in college before I actually knew there were different parts. As for age, I would have to say between 17 and 19. (Jill)

My family had used "vagina" as the counterpart to "penis." "Vagina" was everything a girl had "down there." I knew it was a "third hole" (that was my only concept of what the vagina was, a hole meant to hold a penis and birth a baby). (Jessica)

Furthermore, by reproducing the existent "social regulation of the senses" (Jackson 1977: 209), ignorance persisted throughout women's somatic careers. The majority of women in this study openly admitted that they presently do not know or understand the various parts of the vulva. Jill wrote, "I feel like I don't know or understand the 
different parts of the vagina at all." Similarly, Ann wrote, "I don't feel I know the parts of female genitals very well. ... they look a lot different in real pictures than on drawings or models. . . . I don't know what all the parts do or what all their functions are." While Cheryl claimed to "know the various parts of women's genitals," she immediately added, "I probably wouldn't get them all right on a placement test." Indeed, owing to the colloquial use of "vagina" to refer to all the parts of the vulva, Rebecca was caught off-guard when we asked the question, "How well do you feel you understand the various parts that comprise women's genitals?"

I just reread this question and I'm unsure what it means. The vagina is composed of several different parts? I guess I never knew that. I feel a little ashamed to admit that and a little angry.

Rebecca was not alone in her embarrassment, or anger, as Sara explained:

This is embarrassing, but I don't feel like I know the different parts of my genetalia [sic] at all. I was never, not that I recollect, shown a diagram of a vagina until I came to college. . . . I wish that I knew more about women's anatomy, but it is embarrassing enough to not know these things in the first place.

The women in this study reported a vagueness, lack of knowledge, and even admitted outright ignorance about their genitals- "blind spots in women's knowledge of their bodies, arousal, and desires" (Plante 2006:143). We recognize that "the implications in terms of those women's attitudes toward their own sexuality are serious" (Sanders and Robinson 1979:228) and share Plante's (2006:143) concern "that women may not know their bodies, may not have comfortable language to describe their bodies, and may not know their desires." These are the circumstances and conditions of symbolic clitoridectomy: a form of putting the clitoris under erasure not by way of sheer silencing but by a restrictive economy of discourse-among other significant forces- that confines the clitoris in a symbolic purgatory.

\section{DISCOVERING THE SENSATIONS OF THE CLITORIS}

I discovered the sensations of my clitoris long before I ever properly identified the organ, the source of all the magic. I was probably about 9 or 10 . I had been playing around with myself - not really masturbating, just spelunking my "down there" - and I pulled back some flesh and discovered this amazingly sensitive little knob (it almost felt a little dangerous). It was this hidden, private thing that I gazed at with some hesitancy. My first thought was something along the lines of "What the hell is that?!"

- Jessica

Women rarely acquired symbolic knowledge about the clitoris until their mid- to late teens but were seldom unaware (or innocent); many discovered "it" long before and were well acquainted with the pleasing sensations it provides. Because "children can recognize that touching their genitalia 'feels good"' (Plante 2006:106), it is not 
surprising that many women recalled learning, as a child, that some parts of their genitalia felt more pleasurable than others. As Jill reported,

I discovered my clitoris when I was in third grade. So I was probably about eight. I didn't really know what was going on. I just knew that when I touched a certain spot it would feel really different than when I would touch other places. This discovery usually came along when I couldn’t sleep at night.

Several women gave similar testimonials; clitoral sensations were often something they pleasingly discovered entirely for themselves in confidential, clandestine somatic explorations-often during restless nights or in the bathtub-circumstances that provided a measure of privacy, easy access to the genitals, and perhaps motivation as well:

I remember discovering my clit when I was fairly young. I was around six or seven years old. Laying [sic] in my bed trying to go to sleep, I remember putting my hand down there and feeling around. I discovered I liked how it felt to touch it. (Ann)

I was very young when I began my discovery process. My guess for age is probably eight or nine years old. I remember noticing my clitoris while I was in the bathtub. All I knew at the time was that urine came from somewhere in that general vicinity. (Cindy)

Although unaware that "it" had a name, by discovering its pleasing sensations many women "had" (Dewey [1922] 2002) some of its meanings. In this way, the body makes sense because, in part, the body is sense (Vannini and Waskul 2006). While "it" may lack symbolic meaning, it is bountiful with the iconic meaning and the "qualitative immediacy" that the body provides. Bodily awareness may be hidden or disappear from consciousness until a "sensory intensification" (Leder 1990:71) takes place, allowing body parts "waiting like tools in a box to be used by conscious resolve" (Dewey [1922] 2002:25). This is precisely what Kari reported: "I guess I could say I was little, like ten or eleven when I discovered the good feeling of it being rubbed. ... I knew what 'it' was before I knew it was a clitoris" (emphasis added). Experience cannot be understood through language alone; the body is a site of preobjective knowledge (Dewey [1934] 1958, [1922] 2002). As Frank (1995:27) suggests, "The body is not mute, but it is inarticulate; it does not use speech but it begets it." This form of linguistically "pre-reflexive experience" (Csordas 1990:6) proved equally true for women who reported discovering their clitoris by accident. Danielle recalled her discovery:

The first time I remember having sensations, I was probably nine or ten yrs old, between fourth and fifth grade. I was climbing a pole on the playground and it felt good to climb upwards. I don't remember knowing or understanding what it meant at the time, just that it felt good. I remember not wanting anyone to know why I liked it, although I recall a girlfriend teasing me, so I figured she "knew" too. I don't recall too much from elementary and junior high [school] but I'm guessing I was about fourteen or fifteen when I was using a back massager and it fell into my lap. I suddenly realized what "that" feeling was. I knew I had a clit 
by then, but probably still had not been told that it was for pleasure. I put the massager away and tried to forget about what happened, but the next time I was home alone I decided to explore more. This is when I discovered that the vibrations felt the best on my clit. I liked it but I didn't want anyone to know.

As is apparent in Danielle's account, some women did not recall so freely exploring their body as a child. Both Beth and Sara did not discover the pleasures of their clitoris until a book motivated carnal exploration. As Beth explained:

I had begun reading more mature books that had sex in them, and it made me curious. So I started to experiment touching myself. I was in my bed at night and it was a new and thrilling experience. ... I believe I was in early junior high.... I couldn't believe that my body could feel like that and that I had gone so long without knowing it existed.

Beth was surprised that she "had gone so long without knowing it existed," which is understandable considering that "the possibility of pleasure is literally in [her] own hands" (Plante 2006:144), and always had been.

\section{SYMBOLIC PURGATORY}

A sensation is only pleasurable or enjoyable, not in itself, but in the context of the meaning of the activity in which it is embedded. -Robert Solomon, "Sexual Paradigms" (1997)

Women generally discovered the pleasures of the clitoris long before they knew it had a name, a circumstance we have described as symbolic purgatory. Like Cheryl below, several women remarked on this gap between somatic discovery and discursive knowledge:

I didn't learn about the clitoris specifically until ninth grade (age fourteen). Before that I had learned about the female genitalia in a rather broad sense. I knew there was more to the female genitalia than just a vagina (learned from general discussion with my family/parents, not really any specific age), but I didn't know what each part was called. In ninth grade health class, my teacher passed out very detailed diagram pictures with everything labeled for both female and male genitalia.... In the back of my mind, I vaguely connected the clitoris to the specific part that gave me the most pleasure.

Until learning that their "special spot" is a clitoris, some women-like Sara"just assumed that it was a part of the vagina but with no specific name." Other women, like Ann, "had no idea other people had a spot like this that felt good to touch." As we have suggested, somatic discovery is a sensual and carnal source of both meaning and information for the embodied self. However, somatic discovery is not entirely language free. For example, our informants often used the euphemism "down there"-with all its connotations of everything sexual, naughty, mysterious, unspeakable, devious, and so forth-and this clearly illustrates how the clitoris is neither confined to discursive darkness nor basking in symbolic transparency. The clitoris inhabits an intermediate state (a purgatory), awaiting linguistic conceptualization, 
which is evident in Cheryl's recollection: "I knew for many years that it wasn't just a vagina but [I] never really concerned myself with more than that" (emphasis added). A similar waiting for discursive cues is equally apparent in the accounts of Jessica and Diana:

I always knew there was more going on "down there" than just a hole, but until I was given names and info for the different parts I never really thought much about them. (Jessica; emphasis added)

I don't think I ever consciously thought about "the thing down there" until I learned it had a name. Once it had a name it was something ok; something more real. (Diana; emphasis added)

The relative muting of the clitoris is all the more significant because, as Rebecca claimed, "it [clitoris] does bring me great sexual pleasure, and when I think about it I usually think about the pleasure I get from it." More than mere vocabulary, language may well constitute a lexicon for experience, in this case the experience of pleasure.

Despite a certain kind of will to discursive knowledge (Foucault 1979), many women remained incapable of finding a label (see Weinberg, Williams, and Pryor 1995) for the clitoris for extended periods of time. For example, Jill wrote, "I'm not even sure I fully understood what a clitoris was until I was almost out of high school." Jill's recollection of uncertainty was consistent with the accounts of many women in this study who also reported a period of vagueness:

Even after finding out its name (in biology class) there was still the vagueness of the concept. (Jennifer)

The first time I ever heard the word clitoris was in my seventh grade health class. ... we got a very academic lesson of the female anatomy, but it took me a while to realize the clitoris on the diagram was the same piece of flesh that I would touch at night. (Beth)

In some cases, women reported learning of their clitoris from peers. ${ }^{3}$ As Rochelle explained, she learned of her clitoris in the "later part of high school, from friends my age (mostly the guys talked about it, never the girls)." But her understanding was vague and confused; having heard "the guys talk about it" in reference to oral sex, Rochelle admits, "I didn't know what the clitoris had to do with 'eating out."”

It was popular media sources that most commonly provided the knowledge that "it" is a clitoris - a telling instance of a society that disguises truth in secrecy while also generating multiple discourses through which secrets can be discovered (Foucault 1979). Jill explained, "No one really told me what it was, I just suddenly put my masturbating sensations together with these words that I kept hearing. I think Sunday Night Sex Talk helped me come to the realization." At least Jill recalled learning about her clitoris from a relatively accurate and reliable media source-Sunday Night Sex Talk is a cable broadcast featuring a registered nurse-cum-sex expert. Two women reported learning their "special spot" was called a clitoris from an episode of the cartoon South Park. Ann wrote: 
It is incredibly strange how I learned that my "special" spot was called the clitoris. I had been sexually active for a while and knew that when the spot was "rubbed" right I would orgasm. I was watching either an episode of or the movie South Park and the one character said something about how if you couldn't find a girl's clit you would be a bad boyfriend. This connected in my brain and I formally learned that this place I had been touching for so long and gave me so much pleasure had a name.

Vicki learned "it" was a clitoris from pornography that she and her neighborhood friends "stole" from a parent's less-than-secret stash:

I was about ten, and I knew what porn was. So my neighbors and I decided to steal one and watch it to learn more about sex.... Me and three other girls sat in my basement and watched it and I remember for the first time feeling "turned on." And then in the movie a woman received oral sex and had an orgasm and said something about her clitoris in the process and I just remember everything clicking[; that my clitoris had a lot to do with me being "turned on" and experiencing orgasm.

Although she felt ashamed and conflicted, Diana learned about her clitoris from earnest research:

After learning about "my female self" in fifth grade gym class, I think that's what really sparked my curiosity with sexuality. I remember going through as many encyclopedias, dictionaries, and informational books as I could find for more information, better information, and yes, even juicer information. . . . I was never ashamed to knowing the things I knew, but I was ashamed that I wanted to know and ashamed that I sought things out. I didn't want to feel dirty—but at the same time it felt good to know. It was all very contradictory.

Women were generally relieved to learn "it" was a clitoris. Since language is a cultural stockpile of accepted meaning and truth, simply knowing "it" has a name validates and legitimizes both the clitoris and a young woman's body, femininity, and sexuality. A word renders the clitoris a significant symbol—which is significant, indeed:

I had spent months pleasuring myself before I learned what exactly I was using to do it. It was kind of nice to know my body was working properly. (Beth)

I remember looking down there and kind of wondering about it, to find out later that it felt good, and then had a name. I think I was surprised that it had its own name. It was kind of nice to be able to label it though, and know that it was different from everything else down there. I was excited but embarrassed that I "knew." (Danielle)

Similarly, Ann wrote, "It was a relief to finally know the name." However, Ann also understandably added, "I already knew it was normal, but I thought it was strange I had never learned its function." Her clitoris had been a part of her body all her life, she had already discovered its wonderful pleasures, and yet she was denied basic anatomical knowledge. More than just "strange," some women were resentful: 
As I became aware, I also became resentful because I realized that the clitoral information/definition was kept from me on purpose. This is knowledge that everyone knows, but no one discusses - that frustrates me. (Jennifer)

Withholding anatomical knowledge-either by intent or by the default of silencebegs questions of possession and ownership. At issue is not only the possession of knowledge but, in some cases, ownership of the clitoris itself.

\section{TO WHOM DOES THE CLITORIS BELONG?}

I never met a man who told me he didn't know how to come or didn't know where his penis was. That pretty much sums up the dilemma of women's sexual responsiveness. Lots of women have never even said the word "clitoris" or touched their clit, and don't really have a good idea about their genitals at all. - Suzie Bright, The Sexual State of the Union (1997)

The first time I found out the name of the clitoris I was about sixteen. My boyfriend sort of told me what it was. -Kimberly

"Most women's experiences of sexuality are very partner-focused" (Plante 2006:143), and the same may be true of what is allegedly "her" clitoris. Indeed, as Sara confessed, "It wasn't easy for me to admit that I needed to have my clitoris stimulated in order to orgasm, I was afraid that my boyfriend would be offended." Furthermore, because in large part of a partner-focused sexuality, some women perceive their clitoris as apparently akin to timeshare property, with ambiguous and communal ownership - an area that is for her to use, provided others have not laid claim to it. For example, Diana, who admitted preferring to masturbate with a vibrator, wrote:

My fiancée [sic] is ok with the fact that I have a vibrator since he's gone, and it's ok that I use it, but he won't use it on me and has told me that if I use it while he's in the house he'll really feel upset.

Diana's clitoris is, apparently, an organ that validates her fiancé's sexuality and gender identity, which she is expected to maintain. Diana has permission to touch her own clitoris-to derive somatic pleasure-but only in his absence. It is unclear where Diana's genitals end and her fiancé's begin. The symbolic terrain is thus occupied by social practices and discourses that "deindividualize human sexual experience" by acting as a concerned, curious, fearful, anxious witness (Ajzenstadt and Cavaglion 2002:93).

More strikingly, imagine the surprise of Kimberly and Jennifer, who did not know they had a clitoris until an unexpected moment when a boyfriend discovered it for them. As Kimberly explained, "My discovery of my clitoris happened when I was fifteen. I had been dating a guy for a year and he decided to go down on me. 
All I know is that he flicked his tongue on my clitoris (which I had originally thought pee came out of, when I was little) and it felt really good." Kimberly's pleasure was quite the opposite of Jennifer's response:

I discovered my clitoris in my first sexual relationship, about age fifteen. I, myself, don't think [I] discovered it, but my male sex partner did. We learned that this "button" sent uncontrollable sensations through my body. When it happened, I was slightly confused because I myself didn't know of it. . . . When these encounters happened it was my boyfriend that touched my clitoris, I can't remember if I ever did. I doubt it. I don't think it ever dawned on me to use it by myself. . . My male sex partner enjoyed my physical reaction more than I enjoyed it. I can honestly say it made me uncomfortable. (emphasis in original)

Kimberly and Jennifer's experiences starkly illustrate how erasure can render a woman's clitoris a symbolic, corporeal, and experiential territory that may be occupied by others, in this case, men. A missing or ambivalent discourse of feminine desire (Tolman 1994) potentially renders the clitoris the property of others-a part of her body that is apart from her body, "existing in the shadow of and in light of men's sexual interests and attractions" (Plante 2006:128). Indeed, five years later-at the age of twenty-Jennifer admitted, "My sex partners have used clitoral stimulation and it is pleasurable, but I have yet to explore it myself." Although she recognized her clitoris as a part of her body that brings her pleasure, she only allows others access. Jennifer clarified an awareness of her own denial: she restricts access to her own somatic sensations.

I can honestly say that $I$ have never touched $m y$ clitoris for pleasure. I have used an object for vaginal insertion by myself ONCE. I felt very uncomfortable, and did not get any pleasure from it. I was about sixteen years old. As I recall the experience, I don't think I ever even thought about clitoris stimulation. I think that reflects how little I knew and understood my own genitals. Almost five yrs later and I have never practiced masturbation again. . . . I hope that I will enjoy masturbation, when the time comes that I too will have some fun. This sounds odd, but I plan to masturbate, it just hasn't happened yet. I would love to explore my body by myself but a part of me is hesitant. I plan to overcome that in the near future.... Thinking about it makes me want to explore it through masturbationbut I don't. Instead I hesitate and put off the experience. Then I feel foolish and naïve-which I don't like. (emphasis in original)

Just as symbolic clitoridectomy and symbolic purgatory can render a woman's clitoris the property of others, language and discourse can also empower-precisely what accounts for Jessica's very different narrative:

I learned about the role of the clitoris from feminist writers. As a teenager I hung around with liberally-minded, sex-positive peers. We talked a lot about everything - and it was a comfortable, non-judgmental environment that caused my mind to stretch. Some friends turned me on to Betty Dodson's books as well as other feminist works (e.g., Cunt by Inga Muscio, Vagina Monologues by Eve Ensler, Our Bodies, Ourselves, etc). I was blown away by 
these works. They turned yucky sex ed into something feisty, fun, and revolutionary. They were unapologetic about their sexual lives and desires, and they were kinda bad-ass about it. This impressed me greatly (esp. as a rebellious teenager). They gave me a new concept in how to perceive sexuality-something to be proud of. Most importantly they gave me permission to be curious - they made it cool to be curious. They impressed upon me the importance of masturbation as an act of education and freedom (it helped you learn about your body and desires and it kept you from ever being dependent on other people). It was through these writers and my friends that I came to better understand my clitoris. It was such a relief. (emphasis in original)

Empowered by a timely education on the politics of her genitals, Jessica and her friends redefined the clitoris on their own terms. In contrast to an occupied clitoris, Jessica professed profound independence ("I am dependent on no one"), appreciation for female genitals ("I had never seen anything so fierce, powerful, and aesthetic before. That moment changed the way I felt about my genitals-I'm still in awe"), and concludes, "Turning kids off to the wonders of the body is emotional genital mutilation."

\section{THE USES OF SOMATIC PLEASURE}

[As a child] I used to play with my whole genital region trying to figure out what everything was. I remember that my clitoris was played with more; probably because it felt good. I do remember feeling shameful. My knowledge of sex told me that little girls don't play with themselves. I think that moment has extended through my whole life and dictates my sexual insecurities. I always played with myself in secret cause I was afraid of the consequences of getting caught. This leant a guilty pleasure aspect to sex and the clitoris as a whole. -Cindy

Considering the combined and cumulative effects of symbolic clitoridectomy and the stigma traditionally associated with masturbation-especially among children (Ajzenstadt and Cavaglion 2002) - it is small wonder the clitoris was kept in relative darkness for most of the women in this study. But, as we also illustrated, that darkness is not absolute; the whole area "down there" is shrouded in secrecy and yet subject to becoming visible through a multitude of discourses. This is why women reported-or at least recalled, which is just as significant- discovering their clitoris in circumstances of combined ignorant pleasure and shameful carnal knowledge:

I always thought I was doing something bad, I thought you shouldn't touch yourself in "inappropriate places." I would touch it almost nightly for many years. I think I stopped around 14 or 15 just because I thought it was dirty and I was doing something wrong. (Ann) 
I think I started masturbating or playing with myself at age 9, roughly. I maybe did it a couple times a year if that. As I grew up it interested me more and I did it more. I remember it as my deepest most dirty secret though and I swore I would never tell anyone about what I did. My body wasn't something to be ashamed of, but what I thought about and did was. (Diana)

In view of the relative silence combined with a multitude of confessional discourses that dominate women's understandings of their genitals, it is not particularly surprising that young women who decide to try masturbation might not know what to do. As Sara recalled:

I remember specifically the first time I masturbated. I was in tenth grade and there was all this hype surrounding this masturbation thing for girls. I asked my friend what it was so I went home and tried it that night. I had no idea what I was doing so I just kinda felt around my vagina. I didn't do any clitoral stimulation (I don't think I had an understanding of what "it" was at the time), I just put my fingers in my vagina. I really didn't get a sense of enjoyment from masturbation at that time so I didn't do it again until I was in college. ${ }^{4}$

Having put off masturbation until her college years, Sara effectively denied herself opportunities to learn about the organ she would later discover and regard as the epicenter of her sexuality. Sara wrote that, once she was in college,

One of my friends bought me a cheap vibrator as a joke for my birthday, and it ended up being the best thing she could have done for me! I decided one night that I would give the new toy a whirl, and I had never been so sexually satisfied. I would say that I masturbate 2-3 times a week now. If I didn't rediscover masturbation I probably wouldn't have such a good sex life. I figured out what I liked and what I needed to be satisfied both alone and with my partner.

Sara's narrative is common for the women in this study; negotiating the shame and guilt associated with masturbation is a common experience, as women acquire knowledge of and about their own body, desires, and claiming ownership of their clitoris and sexuality. As Smith (1987:49) notably remarked, women's daily/nightly embodied experiences are "embedded within the particular historical forms of social relations that determine that experience." Thus it is not surprising that some women overcome alienation and reclaim the meanings of their own somatic experiences by "learning the technique" (Becker 1963:46-48) or, in Foucauldian terms, by applying the right technology of care of the self to the desired use of pleasure (Foucault 1988, 1990). For example, Beth reported overcoming her shame and discovering important virtues of masturbation:

[My] attitude has changed. Currently I masturbate almost every single day. I do not think that people should be afraid of or ashamed to masturbate. It is safe and allows people to gain a better understanding of their own bodies, which is particularly useful when teaching a partner how to pleasure you.

Certainly, some women apparently never touched their clitoris, which they discovered in the throes of a sexual encounter. Conversely, for other women in this study, the sensitivity and precise location of their clitoris allows for sensations that 
are not necessarily dependent on direct manipulation. For example, Jessica learned to "perceive the effects" (Becker 1963:48-53) of her clitoris on regular occasion, both "tingly reminders" during routine daily activities as well as some secrets that are perhaps best kept:

I'd say I "encounter" my clitoris as an organ of sexual pleasure several times a day. By that, I mean not just self-stimulation but also the average day-to-day sensations of sitting in class, walking to work, taking a shower and getting tingly reminders. This often occurs when I'm bored-for example, while sitting through a long, dull lecture - and it's like my body's way of telling me that there's still some fun to be had in the world. It's quite nice actually. Kegel exercises coupled with a good fantasy takes the horror out of a 3-hour class. And no one ever knows!

Similarly, Cheryl wrote, "I'm lucky enough to have a fairly accessible clitoris, and simply wearing the right fit of jeans can almost bring me to a minor orgasm." Nonetheless, the majority of the women in this study discovered the pleasures of the clitoris primarily through clandestine exploration of their genitals and masturbationactivities that continue to carry significant stigma and taboo (Ogletree and Ginsburg 2000) — and thus require active (re)negotiations of competing somatic rules.

"Any sensory experience," Carpenter (1973:20) writes, "is partly a skill and any skill can be cultivated." Thus, for many women in this study, cultivating the uses of pleasure-or in Becker's (1963:53-58) words, "learning to enjoy the effects"-overcoming the shame of masturbation, and becoming comfortable touching their own clitoris, proved instrumental in their narrative of personal reckoning with the symbolic purgatory of the clitoris. Indeed, women who shed old somatic rules about masturbation and self-touching often cited enthusiastic benefits of masturbation, namely, the acquisition of useful carnal knowledge:

That [shame of masturbation] changed as I grew up too. I was 19 when I bought my first vibrator, and even then I "was buying it as a joke for someone else." I had wanted one so much sooner. Now I have 2 of them-had 3 but one wore out! My attitude has changed since then. Now my attitude is very open. I'm open about the fact that I do it, that I like it, that I own vibrators, and what I think about it all. (Diana)

Considering all the ways that the clitoris is muted and potentially colonized by others, it is understandable why Jessica so ardently wrote, "Masturbation, for me, is an act of revolution, an act of defiance, and an act of ungodly enjoyment. I'd recommend it to anyone." An act of revolution and defiance, indeed; in masturbation women not only flick a defiant finger at a taboo but also directly act toward and interact with their clitoris-in defiance of prevailing somatic rules, symbolic purgatory, and symbolic clitoridectomy. In short, women masturbate because it feels good. Yet in masturbation women also interact with their clitoris on their own terms and, in the process, potentially evoke important components of their body, sexuality, femininity, and self. It is in this sense that women's somatic work is a "technique of the body" (Mauss [1934] 1973:75). Body techniques, Mauss suggests, share three 
basic characteristics: they are techniques, in that they rely on the operation of certain movements or forms of experience; they are traditional, in that they are acquired through practice or socialization; and they are efficient, in that they are oriented toward fulfilling a goal or function.

\section{CONCLUSION}

It is interesting, but somewhat disturbing, to note the strong tendency for women to report they remain silent and do not refer to their own genitals. - Janet S. Sanders and William L. Robinson,

"Talking and Not Talking about Sex: Male and Female Vocabularies" (1979)

Exploring the hidden complexities of being female is a damn edgy thing to do, and it takes a certain amount of guts and determination. -Jessica

Broadly reflecting on our findings, we note two key conclusions. On the one hand, the women in this study illustrated the consequences of symbolic clitoridectomy and the validity of its many critics and criticisms (see Bennett 1993; Braun and Kitzinger 2001a, 2001b; Braun and Wilkinson 2001; Moore and Clarke 1995; Ogletree and Ginsburg 2000; Scheper-Hughes 1991). Symbolic clitoridectomy creates conditions in which the clitoris is a part of a woman's corporeal body while simultaneously excised from her conceptual body. If we define the "conceptual body" as an abstraction that subsists of significant symbols (primarily language and discourse), then it is also a social structure of knowledge and stock cultural schemas that inform, organize, and configure carnal and sensual experiences. Indeed, as the women in this study candidly reported, the erasure of the clitoris from their conceptual body did not necessarily prevent the carnal discovery of clitoral pleasures, but it did render the clitoris mute, inarticulate, a symbolic terrain that others may occupy-or some combination thereof.

On the other hand, the women in this study equally illustrated that the body may be inscribed by discourse-but it is also made meaningful in action, transaction, and practice even when the symbolic resources to do so are scarce or contradictory. Sensation is, by definition, emergent from acts of sense making. Thus, as the women in this study illustrated, subjectivity—in this case, sensual embodiment-does not exist prior to experience but flows from it. Further, an object's meanings-including a body part and sensations associated with it-reside not in the object itself but in the interaction or transaction of conduct directed toward it and the qualities emanating from it (Dewey [1934] 1958; Mead 1934; also see McCarthy 1984). Indeed, the women in this study are neither "cultural dupes" nor passive victims of symbolic clitoridectomy but active agents who reflexively made and make meaning of their body and its sensual experiences. 
Thus the central dynamic that characterized women's recollections of the discovery of their clitoris is a negotiation between the potential to sense the qualitative immediacy of the body and the ability to make sense of the see-through-secrecies of symbolic purgatory. Both immediate carnal knowledge and emergent and shifting discourses characterize this negotiation. Perceiving the clitoris, using it, naming it, and understanding the significance of the discourses surrounding it is a complex and emergent biographical process: a career, if you will, of somatic discovery.

The women in this study clearly reported a clitoral somatic career marked by important junctures of discovery, knowledge, and meaning making. Three junctures are most apparent: discovering the sensations of the clitoris, putting the clitoris into discourse, and negotiating contested uses of pleasure. Considering that the women in the study narrowly ranged from nineteen to twenty-two years of age, we suggest we have merely conveyed a portion of women's somatic careers with their clitoris-and, moreover, only among Caucasian, primarily heterosexual, rural, middle-class American women who report a mostly positive relationship with their clitoris, and overwhelmingly in the context of partnered relationships with men. There are other permutations of experience that are not represented in our homogeneous sample-race, ethnicity, social class, nationality, and sexual orientation - that might also shape the way women negotiate the meaning of their clitoris - an empirical question worthy of future investigation. Furthermore, we suggest that there may be other important junctures in women's somatic careers with their clitoris as they age, mature, possibly develop long-term committed relationships, and otherwise realize an emergent personhood, femininity, and sexuality. These additional variables are also worthy of future investigation. We should also admit to another obvious limitation: the two principal investigators are young heterosexual males investigating the private sexual experiences of women. Despite our efforts, our own interpretive lens may well have colored our analysis - as can be expected from any investigation of experiences such as these, no matter how cloaked in the mantra of scholarly discourse. Regardless of these possible differences and limitations, this study clearly suggests that these junctures - as well as the ways in which women actively negotiate them - are cued by the symbolic significance bestowed on the vulva and its parts.

Constructions of women's sexuality concern, in large measure, the symbolic significance of the vulva and its parts, and these constructions also reveal much about the politics of the feminine body. A uterine construction magnifies feminine sexuality as primarily familial - a means, site, and anatomy of childbearing. A vaginal construction magnifies feminine sexuality primarily as a passage — a sexuality defined in terms of what penetrates, comes in, and goes out of a woman's genitals. A clitoral construction patently magnifies feminine sexual pleasure. Certainly, women's sexuality is multisited and can, therefore, be legitimately constructed in multiple ways, by multiple stakeholders, for multiple reasons. It is, however, a clitoral construction of female sexuality that is potentially sovereign, autonomous, and active; a sexuality that hinges on a woman's own sensations and experiences of pleasure. Perhaps for this reason-above all others-empirical studies of women's understandings and 
experiences with their clitoris are far from trivial. The clitoris is, in fact, a most poignant site where the symbolic intersects with the corporeal, the sexual with the political, the woman with the female sexual body, the public with the private, and, of course, desire with social control-the resolution of which is no frivolity, certainly not for the women in this study and perhaps not for us all.

\section{NOTES}

1. Symbolic clitoridectomy is distinct from anatomical clitoridectomy, which has received considerable (and global) attention from anthropologists, as well as other scientists and health workers. The multiple and contested meanings and functions of anatomical clitoridectomy epitomize the ontological and epistemological divisions in the cultural sciences, and between the cultural and medical sciences. Our scope in this article is not to review the anthropological literature on this practice (for more information see Medical Anthropology Quarterly 5[1]). As much as possible, we seek to bracket the intercultural meanings and connotations of clitoridectomy.

2. A clear and pertinent example of what we mean by symbolic clitoridectomy and related conditions of symbolic purgatory is expressed in Foucault's four "great strategic unities" of power/ knowledge on and about sexuality. According to Foucault, tactics deployed in the political struggle against children's masturbation resulted in a "pedagogization" of children's sexuality and therefore in its productive constitution as a subject of knowledge and discourse. Pedagogization is thus not a case of repression; "what this actually entail[s], throughout this whole secular campaign that mobilized the adult world around the sex of children, [is] using these tenuous pleasures as a drop, constituting them as secrets (that is, forcing them into hiding so as to make possible their discovery)" (Foucault 1979:43; emphasis added).

3. Other women also reported a similar silence among peers. Even after learning "it" is a clitoris, many women in this study do not recall ever mentioning it again; they were already acculturated to a norm of silence and committed to maintaining it. Indeed, as Diana (age twenty-two) reflects: "[After learning it is called a clitoris,] I still never referred to it openly to anyoneeven as I grew up and my girl friends and I would talk about boys and things we did with our boyfriends. I don't think I remember any of us referring to it by name."

4. Sara's account vividly illustrates how sensory skill acquisition is achieved via a process that Leder (1990:31) coined "incorporation," a "bring[ing] within a body": "A skill [that] is finally and fully learned when something that once was extrinsic, grasped only though explicit rules of example, now comes to pervade . . corporeality." Similarly, in Dewey's ([1922] 2002:126) words, we can understand incorporation as the process whereby acquired habits are reorganized and "modified ... by redirection of impulses."

\section{REFERENCES}

Ajzenstadt, Mimi and Gabriel Cavaglion. 2002. "The Sexual Body of the Young Jew as an Arena of Ideological Struggle, 1821-1948.” Sumbolic Interaction 25:93-116.

Allan, Keith and Kate Burridge. 1991. Euphemism and Dysphemism: Language as a Shield and Weapon. New York: Oxford University Press.

Becker, Howard S. 1963. Outsiders. New York: Free Press.

Bennett, Paula. 1993. "Critical Clitoridectomy: Female Sexual Imagery and Feminist Psychoanalytic Theory." Signs: Journal of Women in Culture and Societv 18:235-59.

Blumer, Herbert. 1954. "What Is Wrong with Social Theory." American Sociological Review 18:3-10.

Braun, Virginia. 1999. "Breaking a Taboo? Talking (and Laughing) about the Vagina." Feminism \& Psvchologv 9:367-72. 
Braun, Virginia and Celia Kitzinger. 2001a. “'Snatch,' 'Hole,' or 'Honey-Pot'? Semantic Categories and the Problem of Nonspecificity in Female Genital Slang." Journal of Sex Research 38:146-58.

_. 2001b. "Telling It Straight? Dictionary Definitions of Women's Genitals." Journal of Sociolinguistics 5(2):214-32.

Braun, Virginia and Sue Wilkinson. 2001. "Socio-Cultural Representations of the Vagina." Journal of Reproductive and Infant Psychology 12:17-32.

Bright, Suzie. 1997. The Sexual State of the Union. New York: Simon and Schuster.

Carpenter, Edmund. 1973. Oh What a Blow That Phantom Gave Me! New York: Holt, Rinehart, and Winston.

Cornog, Martha. 1986. "Naming Sexual Body Parts: Preliminary Patterns and Implications.” Journal of Sex Research 22:393-98.

Crossley, Nick. 1995a. "Bodily Techniques, Agency, and Intercorporeality: On Goffman's Relations in Public." Sociology 29:133-49. - 1995b. "Merleau-Ponty, the Elusive Body, and Carnal Sociology." Body \& Society 2:43-63.

Csordas, Thomas, ed. 1990. Embodiment and Experience: The Existential Ground of Culture and the Self. Cambridge: Cambridge University Press.

DeNora, Tia. 1997. "Music and Erotic Agency—Sonic Resources and Social-Sexual Action.” Bodv \& Society $3: 43-65$.

Dewey, John. 1929. Experience and Nature. Chicago: Open Court. - [1934] 1958. Art as Experience. New York: Capricorn. . [1922] 2002. Human Nature and Conduct. Amherst, NY: Prometheus.

Foucault, Michel. 1979. The History of Sexuality, Volume One: An Introduction. Translated by Robert Hurley. New York: Vintage/Random House.

. 1980. Power/Knowledge: Selected Interviews and Other Writings, 1972-1977. Edited and translated by Colin Gordon. New York: Prometheus Books.

- 1984. "We Other Victorians." Pp. 292-300 in The Foucault Reader, edited by P. Rabinow. New York: Pantheon.

1988. The History of Sexuality, Volume Three: The Care of the Self. Translated by Robert Hurley. New York: Vintage. 1990. The History of Sexuality, Volume Two: The Use of Pleasure. Translated by Robert Hurley. New York: Vintage.

Frank, Arthur. 1995. The Wounded Storyteller: Body, Illness, and Ethics. Chicago: University of Chicago Press.

Gartrell, Nanette and Diane Mosbacher. 1984. "Sex Differences in the Naming of Children's Genitalia." Sex Roles 10:869-76.

Holland, Janet, Caroline Ramazanoglu, Sue Scott, and Rachel Thompson. 1994. "Desire, Risk, and Control: The Body as a Site of Contestation." Pp. 61-79 in AIDS: Setting a Feminist Agenda, edited by L. Doyal, J. Naidoo, and T. Wilton. London: Taylor and Francis.

Jackson, Michael. 1977. The Kuranko: Dimensions of Social Reality in a West African Society. London: Hurst.

Leder, Drew. 1990. The Absent Body. Chicago: University of Chicago Press.

Lerner, H. E. 1976. "Parental Mislabeling of Female Genitals as a Determinant of Penis Envy and Learning Inhibitions in Women." Journal of the American Psychoanalytic Association 24:269-83.

Mauss, Marcel. [1934] 1973. "Techniques of the Body." Economy and Society 70-88.

McCarthy, Doyle. 1984. "Toward a Sociology of the Physical World." Studies in Symbolic Interaction 5:105-21.

McClintock, A. 1992. "Gonad the Barbarian and the Venus Flytrap." Pp. 111-31 in Sex Exposed: Sexuality and the Pornography Debate, edited by L. Segal and M. McIntosh. London: Virago.

Mead, George Herbert. 1934. Mind, Self, and Society. Edited by C. Morris. Chicago: University of Chicago Press.

Moore, Lisa and Adele Clarke. 1995. "Clitoral Conventions and Transgressions: Graphic Representations in Anatomy Texts." Feminist Studies 21:255-302. 
Moustakas, Clark. 1994. Phenomenological Research Methods. London: Thousand Oaks, CA: Sage.

Ogletree, Shirley M. and Harvey J. Ginsburg. 2000. "Kept under the Hood: Neglect of the Clitoris in Common Vernacular." Sex Roles 43:917-26.

Peirce, Charles S. 1958. The Collected Papers of Charles Sanders Peirce. Vols. 1-8. Cambridge, MA: Harvard University Press.

Plante, Rebecca. 2006. Sexualities in Context: A Social Perspective. Boulder, CO: Westview.

Plummer, Ken. 2001. Documents of Life: An Invitation to a Critical Humanism. London: Sage.

Rochberg-Halton, Eugene. 1982. "Qualitative Immediacy and the Communicative Act." Qualitative Sociology 5:162-81.

Sanders, Janet S. and William L. Robinson. 1979. "Talking and Not Talking about Sex: Male and Female Vocabularies." Journal of Communication 29:222-30.

Scheper-Hughes, Nancy. 1991. "The Male Discovery of the Clitoris." Medical Anthropologv 5:25-28.

Simmel, Georg. 1950. The Sociology of Georg Simmel. Edited by K. Wolff. New York: Free Press.

Smith, Dorothy E. 1987. The Everyday World as Problematic. Boston: Northeastern University Press.

Solomon, Robert. [1974] 1997. "Sexual Paradigms." Pp. 21-29 in The Philosophy of Sex: Contemporary Readings, edited by A. Soble. 3rd ed. New York: Rowman and Littlefield.

Strauss, Anselm. 1993. Continual Permutations of Action. New York: Aldine de Gruyter.

Tisdale, Sallie. 1994. Talk Dirty to Me: An Intimate Philosophy of Sex. New York: Anchor.

Tolman, Deborah L. 1994. "Doing Desire: Adolescent Girls' Struggles for/with Sexuality." Gender \& Society 8:324-42.

Turner, Bryan S. 2000. "An Outline of a General Sociology of the Body." Pp. 480-501 in The Blackwell Companion to Social Theory, edited by B. Turner. Malden, MA: Blackwell.

Vannini, Phillip and Dennis Waskul. 2006. "Body Image beyond Dualism." Pp. 183-200 in Body/ Embodiment: Symbolic Interaction and the Sociology of the Body, edited by D. Waskul and P. Vannini. Aldershot, U.K.: Ashgate.

Waskul, Dennis and Phillip Vannini. 2006. Body/Embodiment: Symbolic Interaction and the Sociology of the Body. Aldershot, U.K.: Ashgate.

Weinberg, Martin, Colin Williams, and Douglas Pryor. 1995. Dual Attraction: Understanding Bisexuality. New York: Oxford University Press. 